\title{
Pathogenesis of Food Allergy in the Pediatric Patient
}

\author{
Stacy Chin, M.D. ${ }^{a}$ and Brian P. Vickery, M.D. ${ }^{b}$ \\ ${ }^{a} F e l l o w$, Department of Pediatrics, Division of Pediatric Allergy \& Immunology, Duke University \\ School of Medicine, Durham NC USA \\ ${ }^{b}$ Assistant Professor, Department of Pediatrics, Division of Pediatric Allergy, Immunology, \\ Rheumatology, and Infectious Disease, University of North Carolina School of Medicine, Chapel \\ Hill NC USA
}

\begin{abstract}
In the US and other developed countries, food allergy is a growing epidemic in pediatric populations with a substantial impact on health-related quality of life. As such, there are great efforts underway to unravel the mechanisms of oral mucosal tolerance and to better define the factors related to host and allergen exposure that contribute to the aberrant immune response leading to sensitization and clinical food allergy. Although more research is needed to eventually develop targeted treatment and prevention strategies, this review highlights our current understanding of the pathogenesis of IgE-mediated food allergy.
\end{abstract}

\section{Keywords}

Food allergy; IgE; Allergic sensitization; Dendritic cells; Pathophysiology; Oral tolerance; Pathogenesis; Pediatric

\section{INTRODUCTION}

Food allergy is an adverse health effect arising from a specific immune response that occurs reproducibly on exposure to a given antigen [1]. It is a common, serious, and growing problem in developed countries. Whereas the immune system of all individuals recognized food antigens as foreign, patients with food allergy develop pathological immune responses and can rapidly experience harmful adverse symptoms upon re-exposure. Determining the precise prevalence of food allergy has been challenging since the most reliable indicator of food allergy, the double-blind, placebo-controlled food challenge (DBPCFC), is too difficult or time-consuming to employ in most prevalence studies. Self-reported survey data from the Centers for Disease Control and Prevention indicate that the current prevalence of food allergy in US children is approximately $4 \%$, an increase of nearly $20 \%$ in the last decade [2]. A similar increase has been observed in methodologically rigorous studies from around the world $[3,4]$, suggesting that the rise is not simply due to self-diagnosis or increased recognition.

While food allergy is often considered to result from a failure in oral tolerance, spontaneous clinical tolerance does develop in some food-allergic individuals. Although the process is not entirely clear, resolution tends to occur in allergen-specific patterns. For example,

Corresponding Author: Brian P. Vickery, M.D., UNC Department of Pediatrics, CB\# 7231, Chapel Hill NC 27599, 919-966-2331 (Tel.), 919-966-0135 (fax), bvickery@email.unc.edu.

Disclosure No potential conflicts of interest relevant to this article were reported. 
allergy to egg, milk, wheat, and soy is generally outgrown, whereas most patients remain allergic to peanut and tree nuts and must maintain life-long, strict elimination diets. Even so, it is a common scenario for a child to outgrow an early milk or egg allergy but not a peanut allergy [5]. Therefore, it appears that the pathophysiology of food allergy differs in antigenspecific ways even within the same patient.

Due to an inability to predict the risk of anaphylaxis or determine the eliciting dose threshold, avoidance remains the standard of care [1]; however, even in the most cautious patients, accidental ingestions frequently occur and are often undertreated [5, 6]. The inability to completely eliminate the possibility of anaphylaxis and the associated limitations in everyday activities are great sources of uncertainty and stress for affected families [7]. Over time, health-related quality of life is seriously eroded, to a greater degree than seen in other chronic diseases of childhood [8].

Consequently, great efforts are underway to better understand the mechanisms of oral tolerance and conversely what factors cause them to go awry [9]. While many details remain elusive, this review will cover our current knowledge of the pathogenesis of IgE-mediated food allergy. To date, the majority of mechanistic evidence has been derived from animal models, but we will review the evidence for similar phenomena in humans and the relevant applications for clinical medicine where possible.

\section{GI MUCOSAL IMMUNITY: OVERVIEW}

The gastrointestinal tract, the largest immunologic organ in the body, is exposed to a constant barrage of exogenous antigens on a daily basis [10]. The mucosal immune system has evolved to inhibit responses to harmless antigens (e.g., commensal bacteria, food protein) while maintaining the ability to mount a vigorous protective response when faced with enteropathogens. Homeostasis between tolerance and immunity is therefore an active immune process. This intricate balance can be modified by several factors in the intestine and when disrupted can lead to a breach in oral tolerance and inappropriate allergic sensitization to food proteins. Remarkably, only a single epithelial layer separates this antigenic load from the lymphocytes, antigen presenting cells (APC), stromal cells and other immune cells in the lamina propria, which together comprise the mucosal-associated lymphoid tissue (MALT). Within the MALT, unique populations of dendritic cells (DCs) interact with dietary antigens and determine the fate of the resulting adaptive response, i.e., immunity versus tolerance [11]. In this context, immune tolerance is defined as the antigenspecific suppression of cellular or humoral immune responses. Normally, when the initial antigen exposure occurs through the GI tract, a robust T cell-mediated suppression develops called oral tolerance [12]; however, in 4-6\% of children, this mechanism appears to fail, leading to sensitization and elicitation. We will first consider several factors related to the host and the allergen exposure that may play a role in determining the nature of the immune response.

\section{THE INTRINSIC PHYSICAL PROPERTIES OF FOOD ALLERGENS}

Of the $12,000^{+}$food protein families in existence, a relatively small number cause the majority of food allergies [5]. This fact suggests that the main food allergens - milk, egg, wheat, soy, peanut, tree nuts, fish, and crustacea - though diverse in origin, share common functional characteristics that confer allergenicity: (1) small molecular weight, (2) an abundant source of the relevant allergen, (3) glycosylation residues, (4) water solubility, and (5) resistance to heat and digestion. These properties are unique to food allergens, which unlike inhaled or contact allergens, must pass through the harsh environment of the digestive system. Following ingestion, processing of dietary proteins by salivary and gastric enzymes and gastric acid results in reduced immunogenicity, likely by the destruction of 
conformational epitopes. However, proteins with the above physicochemical properties resist this processing and have allergenic potential upon reaching the small intestine. Factors that disrupt normal digestion such as co-administration of antacids have been shown in animal models to result in a breakdown in oral tolerance induction [13].

Because food antigens are non-self proteins, all normal individuals will mount an immune response $[14,15]$. However, once putative allergens survive the digestion process relatively intact, they must initiate a $\mathrm{T}_{\mathrm{H}} 2$ response in order to result in IgE production and disease expression. While most of the focus in understanding the cellular and molecular basis of allergenicity has been on $\mathrm{T}$ and $\mathrm{B}$ cell epitopes, there is no compelling evidence for the presence of common structural characteristics [16]. Consequently, there has been renewed interest in studying the innate immune system and its activation by allergens [17]. In particular, recent studies have highlighted the emerging importance of the carbohydrate residues, which decorate glycosylated proteins and can act as adjuvants by influencing immunogenicity and $\mathrm{T}_{\mathrm{H}} 2$ polarization [18]. This is not entirely surprising, given that the mucosal IgE system evolved to defend the host from intestinal metazoan parasites, which themselves are heavily glycosylated. Other potentially important features of food allergens include lipid binding as well as higher order macromolecular structures that may promote aggregation and influence transepithelial transport [19].

While some common food allergens may possess self-adjuvant activity promoting sensitization, other foods possess immunomodulatory effects to suppress sensitization. Isoflavones present in soy have recently been shown to hinder allergic sensitization in human DCs as well as protect against peanut allergy in a murine model [20]. Zhou and colleagues [21] demonstrated that binding of sugar-modified antigen to the innate immune receptor SIGN-R1 (murine homolog to human DC-SIGN) could reduce the anaphylactic response to food allergen by inducing DCs to release IL-10 and to generate T-regulatory type 1 cells $(\operatorname{Tr} 1)$. Thus, the specific modulatory effect of a given food antigen on innate immune cells could explain its allergenic potency. For example, peanut and soy proteins share extensive amino acid homology yet confer differing prevalence rates and symptom severity.

\section{ONSET OF SENSITIZATION: GENETICS, TIMING, AND ENVIRONMENT}

Genetics plays a clear role in mouse models in which certain strains have exaggerated $\mathrm{T}_{\mathrm{H}} 2$ bias whereas others resist sensitization [22]. Likewise, familial aggregation in food allergy [23], high concordance rates of peanut allergy among monozygotic twins [24], and certain racial/ethnic predilections [25] suggest that genetics plays a significant role in humans as well. Few genome-wide association studies of food allergy have been performed, and although polymorphisms in genes associated with food allergy have been found in single studies, the results have not been replicated in independent populations [26, 27]. Candidate gene approaches have been largely unsuccessful, with the exception being one case-control study suggesting increased risk of peanut allergy in 71 UK subjects with loss-of-function filaggrin mutations [28]. While genetic susceptibility undoubtedly contributes to the onset of disease, the rise in prevalence is more rapid than genetics can explain, thus drawing attention to environmental factors. Increasing interest in epigenetic modifications may elucidate an important role for heritable gene-environment interactions in food allergy pathogenesis [29].

Although food sensitization is often an early life event [30], it remains controversial whether allergic priming could occur in humans in utero [31-33]. Furthermore, manipulation of the maternal diet during pregnancy and/or lactation has demonstrated little protective effect on the development of food allergy [34, 35]. In mouse models, high-dose exposure to antigen in 
early life, even a single isolated dose, can produce lymphocyte anergy, whereas repeated, low-dose exposure induces tolerance through T-regulatory cell (Treg) development [36]. Emerging evidence in human disease suggests that exposure to the proper dose of antigen during this critical period in early life is important for the shaping of the appropriate immune response to foods. Several epidemiologic studies have implicated delayed weaning patterns in the increased prevalence of peanut allergy [37-39]. Similarly there is evidence that delayed introduction of cereals is associated with a higher risk of wheat allergy [40]. European and American feeding guidelines have recently been revised to reflect the position that insufficient evidence exists to support delayed weaning as a preventative strategy [1, 41, 42]. However, early introduction is not necessarily better, since mature immune regulation may require time [43]. Cow's milk is typically the first potentially allergenic exposure and yet is the most common food to which US children are allergic [5]. In addition, maternal peanut consumption during breastfeeding, but not pregnancy, was associated with peanut sensitization [44]. Defining the most appropriate time and dose for tolerance induction in humans is a great research need. Interventional studies are underway to investigate the importance of early life oral exposure in tolerance development.

The modern rise in food allergy has coincided with a concurrent upsurge in vitamin D deficiency (VDD). A hormone that binds nuclear elements and is known to affect both innate and adaptive immunity, VDD has already been linked to the development of atopic dermatitis [45] and recurrent wheeze [46], leading to the hypothesis that deficiency of this key environmental factor may also play a role in the pathogenesis of food allergy [47]. Supporting evidence includes the influential role of $1,25(\mathrm{OH})_{2} \mathrm{D}$ in Treg development [48], microbiome diversity [49], and mucosal barrier maintenance and repair [50]. Recently, data from the National Health and Nutrition Examination Survey revealed that VDD was associated with higher levels of IgE sensitization to peanut and select aeroallergens in children and adolescents, but not adults [51]. While too common to be individually responsible, VDD is another plausible contributing factor to the increasing prevalence of food allergy.

\section{ROUTE OF EXPOSURE}

The coinciding increase in food allergy with dietary guidelines to delay introduction of allergenic foods has led to the hypothesis that sensitization may occur through non-oral routes. Given the high concurrence rates of food allergy among patients with atopic dermatitis, the skin is of particular interest; as previously noted, filaggrin mutations are thought to confer enhanced risk for peanut allergy. Household peanut consumption has been linked to an increased risk of peanut sensitization in children, independent of maternal peanut intake [38]. In addition, many children experience allergic reactions after their first known oral ingestion [52], suggesting sensitization through previous occult exposure. These observations suggest that oral exposure is tolerogenic by default, while exposure through other routes preferentially induces sensitization. Reinforcing this concept was the finding that UK children with positive oral food challenges to peanut were significantly more likely to have used eczema creams containing peanut oil than atopic or normal controls [31]. Studies of epicutaneous sensitization in murine models are conflicting regarding whether the skin is intrinsically pro-allergenic [53]. Interestingly, epicutaneous immunotherapy is being developed as an experimental treatment for food allergy [54, 55]. In the sections that follow, we will review the mechanisms in the gut that may determine whether a food exposure results in allergy or tolerance. 


\section{MICROBIOME: THE GOOD WITH THE BAD}

A critical influence on the mucosal immune response is the microbial stimulation provided by the enteric flora, which by adulthood number approximately 100 trillion in the large intestine [56]. Within hours of birth, bacteria colonize the neonatal GI tract and begin interacting with the MALT; this probably represents the primary stimulus for proper postnatal immune development, since germ-free mice have disorganized and poorly developed mucosal and secondary lymphoid structures. In the absence of a microbial flora, these animals have impaired antibody responses and do not develop oral tolerance [57]. More recently, a birth cohort study following high-risk children through 6 years of age demonstrated that the bacterial diversity of intestinal flora was inversely associated with the risk of allergic sensitization to foods and aeroallergens, peripheral blood eosinophilia, and allergic rhinitis [58]. However, reduced bacterial diversity was not associated with an increased risk of asthma or atopic dermatitis in the first 6 years of life. Other studies have identified specific differences in the flora of allergic and nonallergic children [59,60]. This suggests that although intestinal microbial colonization is required for proper immune development, certain microbes may play a significant role in skewing the immune response toward allergic sensitization, possibly by suppressing the general biodiversity and creating an environment that enhances the development of allergic disease. Interestingly, a group of investigators has recently linked a decline in environmental biodiversity with a decline in the biodiversity of skin flora in atopic individuals [61], possibly explaining why urban populations are disproportionately affected by allergic disease.

The critical information provided by the microbiome is interpreted through signals from innate pattern recognition receptors (PRR) such as toll-like receptors (TLRs), which play an important role in intestinal homeostasis [62], in the genesis of Tregs [63] and on the outcome of allergic disease [64]. Recently, differences in TLR-mediated microbial responses at birth and over time were found between allergic and nonallergic children, with the latter demonstrating age-related increased responsiveness to these recognition pathways [65]. Additionally, investigators have identified specific microbial products (i.e., polysaccharide A from Bacteroides fragilis) that interact with TLRs and promote downstream induction of Tregs, modulating intestinal inflammation in mouse models of experimental colitis [63]. This differs from the general consensus that TLR4 pathways are both necessary and sufficient for the development of allergen-driven $\mathrm{T}_{\mathrm{H}} 2$ immune responses in the airway $[66,67]$. The intricacy of the innate signaling pathways has made identifying the specific microbial signal(s) that is/are most important in determining the immune response to food antigen in humans particularly challenging. This is evidenced by the overall disappointing results of probiotic trials on the prevention and treatment of allergic disease [68]. However, new deep-sequencing technologies that focus on the unique 16s ribosomal subunit of bacterial RNA rather than culture-based methods are allowing investigators to identify previously unknown organisms [69].

\section{MUCOSAL BARRIER: FIRST LINE OF DEFENSE}

The "first-line" features of mucosal defense include mucin oligosaccharides and antimicrobial peptides that serve to prevent luminal antigens from interacting with the MALT entirely. Secretory IgA also binds to luminal antigens preventing absorption (i.e., "immune exclusion"). However, its specific importance has been controversial since it appears that cellular mechanisms can compensate for impaired immune exclusion [70, 71]. If a potential allergen penetrates these initial physical factors, the intestinal epithelium itself acts as a barrier to sequester luminal antigens from the MALT, and leakiness of this barrier has been postulated to result in allergic sensitization. Structural integrity of the intestinal epithelium is conferred by adherens junctions and tight junctions, but it may take years for 
complete developmental maturation of the gut barrier in healthy children [72]. In mice, the permeability of this barrier is further influenced by environmental exposures that result in changes in gene expression and phosphorylation of tight junction proteins such as occludins, claudins, and JAM-ZO1 proteins, which in turn are associated with changes in intestinal mast cells and allergic sensitization [73, 74].

Interestingly, examination of the lactulose/mannitol ratio in urine revealed that food-allergic infants had increased intestinal permeability when compared to healthy children [75]. Even following a minimum 6-month period of allergen avoidance, the intestinal permeability in food-allergic children remained increased. Further evidence linking intestinal epithelial barrier dysfunction and food allergy comes from studies in patients who developed food allergy after solid-organ transplantation while taking calcineurin inhibitors. While initially assumed to result from the transfer of sensitized donor lymphocytes, it is now theorized that medication-induced decreases in cellular ATP altered the integrity of junctional complexes, resulting in increased intestinal permeability [76].

Increasing evidence suggests that the mucosal epithelium is more than simply an inert physical barrier. Epithelial cells express MHC class II molecules and thus may act as nonprofessional APCs that lack conventional co-stimulatory molecules, thus favoring anergy or tolerance [77]. In addition, factors derived from the gut epithelium are generally believed to condition the DCs in the stroma, dampening immune responses and promoting gut homeostasis [78]. One such factor is retinoic acid (RA), which in combination with TGF- $\beta$ is essential for the differentiation of Treg-inducing DCs [79]. Another factor constitutively expressed by the gut epithelium is thymic stromal lymphopoetin (TSLP). TSLP is an IL-7 like cytokine that can activate expression of OX40L on DCs and drive $\mathrm{T}_{\mathrm{H}} 2$ differentiation. Although TSLP has demonstrated a regulatory role in the gut by limiting deleterious $T_{H} 1$ and $T_{H} 17$ inflammation in models of helminth infection and colitis [80], other studies have shown that TSLP amplifies $\mathrm{T}_{\mathrm{H}} 2$ responses directly from $\mathrm{CD} 4{ }^{+} \mathrm{T}$ cells and is required for allergic inflammation although not for sensitization or tolerance [81].

Furthermore, a recent study illustrated that TSLP promotes systemic basophilia, resulting in increased $\mathrm{T}_{\mathrm{H}} 2$ cytokines and IgE [82].

\section{INNATE IMMUNITY: DENDRITIC CELLS SET THE STAGE}

If food proteins survive digestion and evade luminal defenses, they will be detected by APCs in the MALT in the context of signals provided by the commensal flora. In this way, a complex interplay of all aforementioned factors (i.e., antigen character, dose, timing, and innate immune stimulation) will determine the immune response to an ingested food protein through the same final common pathway: by directly or indirectly influencing the APC. Mucosal DCs are probably the most critical determinant of allergic sensitization versus tolerance in naïve individuals, largely because of their location and their capacity to receive and interpret environmental signals, which lead to a specific immune response. These DCs can encounter ingested antigen in one of three ways: by extending dendrites through the paracellular space between epithelial cells to sample luminal contents, by directly interacting with the epithelial cells, and by taking up antigen in Peyer's patch, specialized lymphoid tissue that is immediately adjacent to microfold cells [83]. The properties of the antigen itself - particulate versus soluble - to a certain extent determine the route of exposure.

One of the more recent advancements fostering our understanding of oral tolerance is the characterization of two critically important and developmentally distinct subsets of intestinal DCs that can be discriminated by the cell surface expression of either CD103 or CX3CR1 $[84,85]$. Of these two populations, only $\mathrm{CD} 103^{+} \mathrm{DCs}$ are able to migrate from the lamina propria to the mesenteric lymph node (MLN); thus, the CX3CR $1^{+}$cells (which are $\mathrm{CD} 103^{-}$) 
are more appropriately categorized as intestinal macrophages. After acquiring antigen, $\mathrm{CD} 103^{+} \mathrm{DCs}$ migrate from the lamina propria to the MLN in a CCR7-dependent manner (Figure 1) [86]. These specialized DCs express the enzyme retinaldehyde dehydrogenase 2, which converts the vitamin A metabolite retinal to RA. In the presence of TGF- $\beta$, which is also produced by $\mathrm{CD} 103^{+} \mathrm{DC}$, RA can promote the differentiation of naïve $\mathrm{T}$ cells within the MLN into Foxp3-expressing Tregs. Moreover, the CD103 ${ }^{+} \mathrm{DC}$ uses RA to imprint naïve T cells with the gut homing markers integrin a $4 \beta 7$ and chemokine receptor CCR9. Further contributing to their tolerogenic capabilities, $\mathrm{CD} 103^{+} \mathrm{DCs}$ also express the enzyme indoleamine 2,3 dioxygenase (IDO), which serves to inhibit the generation of T-effector cells by metabolizing tryptophan and producing toxic byproducts [87]. Inhibition of IDO abrogates the development of inducible Foxp $3^{+}$Tregs in vitro and prevents the development of oral tolerance in vivo [88]. This finding along with defective oral tolerance in CCR7deficient mice suggests that $\mathrm{CD} 103^{+} \mathrm{DCs}$ are critical to the induction of oral tolerance. Recently, two studies $[89,90]$ definitively established that a $4 \beta 7$, CCR9 expressing Foxp $3^{+}$Tregs are required for oral tolerance. Using DEREG mice that selectively express the diphtheria toxin receptor on Foxp $3^{+}$cells, investigators demonstrated the reversal of oral tolerance following ablation of Foxp $3^{+} \mathrm{T}$ cells with diphtheria toxin after antigen feeding. While $\mathrm{CD} 103^{+} \mathrm{DCs}$ are essential to oral tolerance induction, intestinal CX3CR $1^{+}$ macrophages are necessary to sustain local tolerance induction [89]. This subset of DC expands FoxP $3^{+}$Tregs in the lamina propria, produces IL-10, and clears bacteria that breach the epithelial barrier. Exploiting the inherently tolerogenic characteristics of CD103 ${ }^{+} \mathrm{DC}-$ for example, by targeting delivery of a specific antigen, could represent a potential treatment modality in the future, although a much greater understanding of their biology is first needed.

The acquisition of $\mathrm{CD} 103^{+} \mathrm{DC}$ 's unique tolerogenic properties likely requires a specific milieu of local conditioning factors provided by intestinal epithelial cells (IECs), commensal bacteria, and dietary constituents. The differentiation of $\mathrm{CD}_{103}{ }^{+} \mathrm{DC}$ depends upon RA and TGF- $\beta$ produced by the IECs [79]. Commensal bacteria such as Bacteroides and

Bifidobacteria strains are capable of directly inducing monocyte-derived DC to acquire a tolerogenic phenotype [56]. Signaling through certain members of the CLR family (e.g., dectin-1, SIGN-R1) upon recognition of microbial glycans also leads to induction of oral tolerance [21]. Depletion of vitamin A and tryptophan from the diet (the only source for these nutrients in mammals) hinders the tolerogenic effect of $\mathrm{CD} 103^{+} \mathrm{DC}$ by hampering their ability to generate Tregs and imprint gut homing receptors on lymphocytes [87].

Exactly what factors skew the $\mathrm{CD} 103^{+} \mathrm{DC}$ toward a non-tolerogenic phenotype or perhaps propagate a different proallergenic DC subset are not entirely clear. However, the potential pathways involved have been highlighted by experiments using adjuvants to orally sensitize mice [53]. Feeding of cholera toxin (CT) alters the migration of $\mathrm{CD} 103^{+} \mathrm{DC}$ from the lamina propria to the MLN and enhances their maturation, leading to enhanced T cell priming [91]. Upregulation of OX40L in the $\mathrm{CD} 103^{+} \mathrm{DC}$ was responsible for an increase in IL-4 and IL-13 by T-effector cells and for the sensitizing capabilities of CT [92]. Within the lamina propria, allergic sensitization was also associated with an increase in $\mathrm{CD} 11 \mathrm{~b}^{+} \mathrm{DC}$ and relative decrease in the $\mathrm{CD} 103^{+} \mathrm{DC}$ subset [93], indicating that the phenotype of intestinal DC determines the immune response to antigen. While $\mathrm{CT}$ is unlikely to play a role in human food allergy, Staphylococcal enterotoxin B (SEB) is a toxin produced by some strains of Staphylococcus aureus. SEB is frequently found as a contaminant in the food supply and frequently produced by colonizing strains present on the skin of atopic dermatitis patients [94]. As an oral adjuvant in mouse models of sensitization, SEB has exhibited an ability to increase $\mathrm{T}_{\mathrm{H}} 2$ cytokine expression and decrease TGF- $\beta$ and Foxp3 expression in vitro [95]. Furthermore, SEB acts directly on DCs to upregulate TIM- 4 expression, which drives $\mathrm{T}_{\mathrm{H}} 2$ cytokine production in T-effector cells [96]. TIM-4 expressed on DCs and its ligand TIM-1 
on $\mathrm{T}$ cells have been shown to be critical regulators of $\mathrm{T}_{\mathrm{H}} 2$ differentiation in humans and mice [96, 97]. Similar to CT, TSLP-stimulated DCs act through OX40L to induce $\mathrm{T}_{\mathrm{H}} 2$ cells and thus may serve as a natural adjuvant when expressed by IECs. Determining additional environmental factors that are capable of modulating molecules such as OX-40L and TIM-4 on gastrointestinal DCs may identify factors potentially responsible for the steep increase in the incidence of food allergy in recent years.

If the DC-food allergen interaction fails to induce tolerance, the ensuing immune response proceeds through two phases: allergic sensitization and elicitation. Allergic sensitization involves T cell priming after DC activation, and the resultant T-helper-2 $\left(\mathrm{T}_{\mathrm{H}} 2\right)$ response is characterized by the production of interleukin-4 (IL-4), IL-5, and IL-13 from CD4+T cells. This $\mathrm{T}_{\mathrm{H}} 2$ response leads to $\mathrm{B}$-cell $\operatorname{IgE}$ production, and this IgE binds to its high-affinity receptor on the surface of mast cells in the skin, gut, and respiratory and cardiovascular systems, arming them for reactivity upon re-exposure to allergen. The elicitation of classic allergic symptoms occurs within minutes after allergen exposure, when IgE-bound mast cells recognize the allergen and become activated [14].

\section{CONCLUSIONS}

Although food allergy affects 12 million Americans, it is remarkable that it is not more common considering the complexities of the mucosal immune system. Robust immunologic mechanisms involving both humoral and cell-mediated responses have evolved to maintain a homeostatic environment amidst the literally billions of antigens within the intestine. In order to incite the allergic cascade, an ingested protein must circumvent this tolerogenic system. Several interrelated factors such as genetic susceptibility and age of the host; antigen timing, dose, and route of exposure; enteric microbiome; and dietary constituents can influence the immune response toward oral tolerance or sensitization and clinical food allergy. More insight into these complex interactions will be essential to developing targeted treatments for food allergy and eventually primary prevention strategies.

\section{Acknowledgments}

This work was funded in part by National Institutes of Health (NIH) T32 Training Grant 5T32-AI007062-32; NIH 1K23AI099083; the NIAID; the Foundation of the American College of Allergy, Asthma, and Immunology; the Thrasher Research Fund; the American Lung Association; and the University of North Carolina Department of Pediatrics

\section{REFERENCES}

1. Boyce JA, Assa'ad A, Burks AW, et al. Guidelines for the diagnosis and management of food allergy in the United States: report of the NIAID-sponsored expert panel. J Allergy Clin Immunol. 2010; 126:S1-S58. [PubMed: 21134576]

2. Branum AM, Lukacs SL. Food allergy among children in the United States. Pediatrics. 2009; 124:1549-1555. [PubMed: 19917585]

3. Venter C, Hasan Arshad S, Grundy J, et al. Time trends in the prevalence of peanut allergy: three cohorts of children from the same geographical location in the UK. Allergy. 2010; 65:103-108. [PubMed: 20078504]

4. Osborne NJ, Koplin JJ, Martin PE, et al. Prevalence of challenge-proven IgE-mediated food allergy using population-based sampling and predetermined challenge criteria in infants. J Allergy Clin Immunol. 2011; 127:668-676. e661-e662. [PubMed: 21377036] This important Australian study used oral food challenges in a population-based sample to determine the prevalence of IgEmediated food allergy to common food allergens.

5. Sicherer SH, Sampson HA. Food allergy. J Allergy Clin Immunol. 2010; 125:S116-S125. [PubMed: 20042231] 
6. Fleischer DM, Perry TT, Atkins D, et al. Allergic reactions to foods in preschool-aged children in a prospective observational food allergy study. Pediatrics. 2012; 130:e25-e32. [PubMed: 22732173]

7. Gupta RS, Springston EE, Smith B, et al. Food allergy knowledge, attitudes, and beliefs of parents with food-allergic children in the United States. Pediatr Allergy Immunol. 2010; 21:927-934. [PubMed: 20492544]

8. Cummings AJ, Knibb RC, King RM, Lucas JS. The psychosocial impact of food allergy and food hypersensitivity in children, adolescents and their families: a review. Allergy. 2010; 65:933-945. [PubMed: 20180792]

9. Vickery BP, Scurlock AM, Jones SM, Burks AW. Mechanisms of immune tolerance relevant to food allergy. J Allergy Clin Immunol. 2011; 127:576-584. quiz 585-576. [PubMed: 21277624]

10. Chehade M, Mayer L. Oral tolerance and its relation to food hypersensitivities. J Allergy Clin Immunol. 2005; 115:3-12. quiz 13. [PubMed: 15637539]

11. Coombes JL, Powrie F. Dendritic cells in intestinal immune regulation. Nat Rev Immunol. 2008; 8:435-446. [PubMed: 18500229]

12. Faria AMC, Weiner HL. Oral tolerance. Immunol Rev. 2005; 206:232-259. [PubMed: 16048553]

13. Untersmayr E, Jensen-Jarolim E. The role of protein digestibility and antacids on food allergy outcomes. J Allergy Clin Immunol. 2008; 121:1301-1308. quiz 1309-1310. [PubMed: 18539189]

14. Gould HJ, Sutton BJ. IgE in allergy and asthma today. Nat Rev Immunol. 2008; 8:205-217. [PubMed: 18301424]

15. Husby S, Oxelius VA, Teisner B, et al. Humoral immunity to dietary antigens in healthy adults. Occurrence, isotype and $\mathrm{IgG}$ subclass distribution of serum antibodies to protein antigens. Int Arch Allergy Appl Immunol. 1985; 77:416-422. [PubMed: 4018884]

16. Traidl-Hoffmann C, Jakob T, Behrendt H. Determinants of allergenicity. J Allergy Clin Immunol. 2009; 123:558-566. [PubMed: 19152966]

17. Wills-Karp M. Allergen-specific pattern recognition receptor pathways. Curr Opin Immunol. 2010; 22:777-782. [PubMed: 21093238]

18. Berin MC, Shreffler WG. T(H)2 adjuvants: implications for food allergy. J Allergy Clin Immunol. 2008; 121:1311-1320. [PubMed: 18539190]

19. Masilamani M, Commins S, Shreffler W. Determinants of food allergy. Immunol Allergy Clin North Am. 2012; 32:11-33. [PubMed: 22244230]

20. Masilamani M, Wei J, Bhatt S, et al. Soybean isoflavones regulate dendritic cell function and suppress allergic sensitization to peanut. J Allergy Clin Immunol. 2011; 128:1242-1250. e1241. [PubMed: 21696815]

21. Zhou Y, Kawasaki H, Hsu SC, et al. Oral tolerance to food-induced systemic anaphylaxis mediated by the C-type lectin SIGNR1. Nat Med. 2010; 16:1128-1133. [PubMed: 20835248] This paper demonsrated a novel method of inducing oral tolerance in mice through sugar-modified antigens which signal through an innate immune receptor.

22. Berin MC, Zheng Y, Domaradzki M, et al. Role of TLR4 in allergic sensitization to food proteins in mice. Allergy. 2006; 61:64-71. [PubMed: 16364158]

23. Hourihane JO, Dean TP, Warner JO. Peanut allergy in relation to heredity, maternal diet, and other atopic diseases: results of a questionnaire survey, skin prick testing, and food challenges. BMJ. 1996; 313:518-521. [PubMed: 8789975]

24. Sicherer SH, Furlong TJ, Maes HH, et al. Genetics of peanut allergy: a twin study. J Allergy Clin Immunol. 2000; 106:53-56. [PubMed: 10887305]

25. Kumar R, Tsai HJ, Hong X, et al. Race, ancestry, and development of food-allergen sensitization in early childhood. Pediatrics. 2011; 128:e821-e829. [PubMed: 21890831]

26. Hong X, Tsai H-J, Wang X. Genetics of food allergy. Curr Opin Pediatr. 2009; 21:770-776. [PubMed: 19851108]

27. Tan TH, Ellis JA, Saffery R, Allen KJ. The role of genetics and environment in the rise of childhood food allergy. Clin Exp Allergy. 2012; 42:20-29. [PubMed: 21771119]

28. Brown SJ, Asai Y, Cordell HJ, et al. Loss-of-function variants in the filaggrin gene are a significant risk factor for peanut allergy. J Allergy Clin Immunol. 2011; 127:661-667. [PubMed: 21377035] This is one of the few successful attempts to identify a genetic risk factor in the 
pathogenesis of food allergy by linking filaggrin gene mutations to an increased risk of peanut allergy regardless of atopic dermatitis status.

29. Prescott S, Allen KJ. Food allergy: riding the second wave of the allergy epidemic. Pediatr Allergy Immunol. 2011; 22:155-160. [PubMed: 21332796]

30. Sicherer SH, Wood RA, Stablein D, et al. Immunologic features of infants with milk or egg allergy enrolled in an observational study (Consortium of Food Allergy Research) of food allergy. J Allergy Clin Immunol. 2010; 125:1077-1083. [PubMed: 20451041]

31. Lack G, Fox D, Northstone K, Golding J. Factors associated with the development of peanut allergy in childhood. N Engl J Med. 2003; 348:977-985. [PubMed: 12637607]

32. Hide DW, Matthews S, Tariq S, Arshad SH. Allergen avoidance in infancy and allergy at 4 years of age. Allergy. 1996; 51:89-93. [PubMed: 8738513]

33. Holt PG. Prenatal versus postnatal priming of allergen specific immunologic memory: the debate continues. J Allergy Clin Immunol. 2008; 122:717-718. [PubMed: 19014763]

34. Herrmann ME, Dannemann A, Gruters A, et al. Prospective study of the atopy preventive effect of maternal avoidance of milk and eggs during pregnancy and lactation. Eur J Pediatr. 1996; 155:770-774. [PubMed: 8874109]

35. Hattevig G, Kjellman B, Sigurs N, et al. The effect of maternal avoidance of eggs, cow's milk, and fish during lactation on the development of $\mathrm{IgE}, \operatorname{IgG}$, and IgA antibodies in infants. J Allergy Clin Immunol. 1990; 85:108-115. [PubMed: 2299096]

36. Burks A, Laubach S, Jones S. Oral tolerance, food allergy, and immunotherapy: Implications for future treatment. Journal of Allergy and Clinical Immunology. 2008; 121:1344-1350. [PubMed: 18410959]

37. Du Toit G, Katz Y, Sasieni P, et al. Early consumption of peanuts in infancy is associated with a low prevalence of peanut allergy. J Allergy Clin Immunol. 2008; 122:984-991. [PubMed: 19000582]

38. Fox AT, Sasieni P, du Toit G, et al. Household peanut consumption as a risk factor for the development of peanut allergy. J Allergy Clin Immunol. 2009; 123:417-423. [PubMed: 19203660]

39. Joseph CL, Ownby DR, Havstad SL, et al. Early complementary feeding and risk of food sensitization in a birth cohort. J Allergy Clin Immunol. 2011; 127:1203-1210. e1205. [PubMed: 21458850]

40. Poole JA, Barriga K, Leung DYM, et al. Timing of initial exposure to cereal grains and the risk of wheat allergy. Pediatrics. 2006; 117:2175-2182. [PubMed: 16740862]

41. Greer FR, Sicherer SH, Burks AW. Effects of early nutritional interventions on the development of atopic disease in infants and children: the role of maternal dietary restriction, breastfeeding, timing of introduction of complementary foods, and hydrolyzed formulas. Pediatrics. 2008; 121:183-191. [PubMed: 18166574]

42. Host A, Halken S, Muraro A, et al. Dietary prevention of allergic diseases in infants and small children. Pediatr Allergy Immunol. 2008; 19:1-4. [PubMed: 18199086]

43. Strobel S, Ferguson A. Immune responses to fed protein antigens in mice. 3. Systemic tolerance or priming is related to age at which antigen is first encountered. Pediatr Res. 1984; 18:588-594. [PubMed: 6332297]

44. Sicherer SH, Wood RA, Stablein D, et al. Maternal consumption of peanut during pregnancy is associated with peanut sensitization in atopic infants. J Allergy Clin Immunol. 2010; 126:11911197. [PubMed: 21035177]

45. Sidbury R, Sullivan AF, Thadhani RI, Camargo CA Jr. Randomized controlled trial of vitamin D supplementation for winter-related atopic dermatitis in Boston: a pilot study. Br J Dermatol. 2008; 159:245-247. [PubMed: 18489598]

46. Ginde AA, Mansbach JM, Camargo CA Jr. Vitamin D, respiratory infections, and asthma. Curr Allergy Asthma Rep. 2009; 9:81-87. [PubMed: 19063829]

47. Vassallo MF, Camargo CA Jr. Potential mechanisms for the hypothesized link between sunshine, vitamin D, and food allergy in children. J Allergy Clin Immunol. 2010; 126:217-222. [PubMed: 20624647] 
48. Unger WW, Laban S, Kleijwegt FS, et al. Induction of Treg by monocyte-derived DC modulated by vitamin D3 or dexamethasone: differential role for PD-L1. Eur J Immunol. 2009; 39:31473159. [PubMed: 19688742]

49. Salzman NH, Hung K, Haribhai D, et al. Enteric defensins are essential regulators of intestinal microbial ecology. Nat Immunol. 2010; 11:76-83. [PubMed: 19855381]

50. Kong J, Zhang Z, Musch MW, et al. Novel role of the vitamin D receptor in maintaining the integrity of the intestinal mucosal barrier. Am J Physiol Gastrointest Liver Physiol. 2008; 294:G208-G216. [PubMed: 17962355]

51. Sharief S, Jariwala S, Kumar J, et al. Vitamin D levels and food and environmental allergies in the United States: results from the National Health and Nutrition Examination Survey 2005-2006. J Allergy Clin Immunol. 2011; 127:1195-1202. [PubMed: 21329969] The first study to demonstrate an association between vitamin D deficiency and allergic sensitization and disease in the pediatric population.

52. Green TD, LaBelle VS, Steele PH, et al. Clinical characteristics of peanut-allergic children: recent changes. Pediatrics. 2007; 120:1304-1310. [PubMed: 18055680]

53. Berin MC. Mechanisms of allergic sensitization to foods: bypassing immune tolerance pathways. Immunol Allergy Clin North Am. 2012; 32:1-10. [PubMed: 22244229]

54. Dioszeghy V, Mondoulet L, Dhelft V, et al. Epicutaneous immunotherapy results in rapid allergen uptake by dendritic cells through intact skin and downregulates the allergen-specific response in sensitized mice. Journal of Immunology. 2011; 186:5629-5637.

55. Mondoulet L, Dioszeghy V, Vanoirbeek JA, et al. Epicutaneous immunotherapy using a new epicutaneous delivery system in mice sensitized to peanuts. Int Arch Allergy Immunol. 2011; 154:299-309. [PubMed: 20962535]

56. Round JL, Mazmanian SK. The gut microbiota shapes intestinal immune responses during health and disease. Nat Rev Immunol. 2009; 9:313-323. [PubMed: 19343057]

57. Mowat AM, Parker LA, Beacock-Sharp H, et al. Oral tolerance: overview and historical perspectives. Ann N Y Acad Sci. 2004; 1029:1-8. [PubMed: 15806729]

58. Bisgaard H, Li N, Bonnelykke K, et al. Reduced diversity of the intestinal microbiota during infancy is associated with increased risk of allergic disease at school age. J Allergy Clin Immunol. 2011; 128:646-652. e641-e645. [PubMed: 21782228] This is one of the first studies to explore the influence of the human microbiome on risk of allergic disease and sensitization in children.

59. Bjorksten B, Sepp E, Julge K, et al. Allergy development and the intestinal microflora during the first year of life. J Allergy Clin Immunol. 2001; 108:516-520. [PubMed: 11590374]

60. Kalliomaki M, Kirjavainen P, Eerola E, et al. Distinct patterns of neonatal gut microflora in infants in whom atopy was and was not developing. J Allergy Clin Immunol. 2001; 107:129-134. [PubMed: 11150002]

61. Hanski I, von Hertzen L, Fyhrquist N, et al. Environmental biodiversity, human microbiota, and allergy are interrelated. Proc Natl Acad Sci U S A. 2012; 109:8334-8339. [PubMed: 22566627]

62. Rakoff-Nahoum S, Paglino J, Eslami-Varzaneh F, et al. Recognition of commensal microflora by toll-like receptors is required for intestinal homeostasis. Cell. 2004; 118:229-241. [PubMed: 15260992]

63. Round JL, Mazmanian SK. Inducible Foxp3+ regulatory T-cell development by a commensal bacterium of the intestinal microbiota. Proc Natl Acad Sci U S A. 2010; 107:12204-12209. [PubMed: 20566854]

64. Holt PG, Strickland DH. Soothing signals: transplacental transmission of resistance to asthma and allergy. J Exp Med. 2009; 206:2861-2864. [PubMed: 19995954]

65. Tulic MK, Hodder M, Forsberg A, et al. Differences in innate immune function between allergic and nonallergic children: new insights into immune ontogeny. J Allergy Clin Immunol. 2011; 127:470-478. e471. [PubMed: 21093030] This study suggests that developmental differences in the innate immune function of children with allergic disease may contribute to differences in postnatal adaptive $\mathrm{T}$ cell immunity.

66. Hammad H, Chieppa M, Perros F, et al. House dust mite allergen induces asthma via Toll-like receptor 4 triggering of airway structural cells. Nat Med. 2009; 15:410-416. [PubMed: 19330007] 
67. Tan AM, Chen HC, Pochard P, et al. TLR4 signaling in stromal cells is critical for the initiation of allergic Th2 responses to inhaled antigen. Journal of Immunology. 2010; 184:3535-3544.

68. Yao T-C, Chang C-J, Hsu Y-H, Huang J-L. Probiotics for allergic diseases: realities and myths. Pediatr Allergy Immunol. 2010; 21:900-919. [PubMed: 20003066]

69. Medini D, Serruto D, Parkhill J, et al. Microbiology in the post-genomic era. Nat Rev Microbiol. 2008; 6:419-430. [PubMed: 18475305]

70. Brandtzaeg P. Update on mucosal immunoglobulin A in gastrointestinal disease. Curr Opin Gastroenterol. 2010; 26:554-563. [PubMed: 20693891]

71. Karlsson MR, Johansen FE, Kahu H, et al. Hypersensitivity and oral tolerance in the absence of a secretory immune system. Allergy. 2010; 65:561-570. [PubMed: 19886928]

72. Dahan S, Roth-Walter F, Arnaboldi P, et al. Epithelia: lymphocyte interactions in the gut. Immunol Rev. 2007; 215:243-253. [PubMed: 17291293]

73. Forbes EE, Groschwitz K, Abonia JP, et al. IL-9- and mast cell-mediated intestinal permeability predisposes to oral antigen hypersensitivity. J Exp Med. 2008; 205:897-913. [PubMed: 18378796]

74. Groschwitz KR, Hogan SP. Intestinal barrier function: molecular regulation and disease pathogenesis. J Allergy Clin Immunol. 2009; 124:3-20. quiz 21-22. [PubMed: 19560575]

75. Ventura MT, Polimeno L, Amoruso AC, et al. Intestinal permeability in patients with adverse reactions to food. Dig Liver Dis. 2006; 38:732-736. [PubMed: 16880015]

76. Levy Y, Davidovits M, Cleper R, Shapiro R. New-onset post-transplantation food allergy in children--is it attributable only to the immunosuppressive protocol? Pediatr Transplant. 2009; 13:63-69. [PubMed: 18179638]

77. Hershberg RM, Cho DH, Youakim A, et al. Highly polarized HLA class II antigen processing and presentation by human intestinal epithelial cells. J Clin Invest. 1998; 102:792-803. [PubMed: 9710448]

78. Iliev ID, Matteoli G, Rescigno M. The yin and yang of intestinal epithelial cells in controlling dendritic cell function. J Exp Med. 2007; 204:2253-2257. [PubMed: 17893197]

79. Iliev ID, Mileti E, Matteoli G, et al. Intestinal epithelial cells promote colitis-protective regulatory T-cell differentiation through dendritic cell conditioning. Mucosal Immunol. 2009; 2:340-350. [PubMed: 19387433]

80. Ziegler SF, Artis D. Sensing the outside world: TSLP regulates barrier immunity. Nat Immunol. 2010; 11:289-293. [PubMed: 20300138]

81. Blazquez AB, Mayer L, Berin MC. Thymic stromal lymphopoietin is required for gastrointestinal allergy but not oral tolerance. Gastroenterology. 2010; 139:1301-1309. [PubMed: 20600023]

82. Siracusa MC, Saenz SA, Hill DA, et al. TSLP promotes interleukin-3-independent basophil haematopoiesis and type 2 inflammation. Nature. 2011; 477:229-233. [PubMed: 21841801]

83. Mowat AM. Anatomical basis of tolerance and immunity to intestinal antigens. Nat Rev Immunol. 2003; 3:331-341. [PubMed: 12669023]

84. Scott CL, Aumeunier AM, Mowat AM. Intestinal CD103+ dendritic cells: master regulators of tolerance? Trends Immunol. 2011; 32:412-419. [PubMed: 21816673]

85. Ruiter B, Shreffler WG. The role of dendritic cells in food allergy. J Allergy Clin Immunol. 2012; 129:921-928. [PubMed: 22464669]

86. Jang MH, Sougawa N, Tanaka T, et al. CCR7 is critically important for migration of dendritic cells in intestinal lamina propria to mesenteric lymph nodes. Journal of Immunology. 2006; 176:803810.

87. Fallarino F, Grohmann U, You S, et al. The combined effects of tryptophan starvation and tryptophan catabolites down-regulate $\mathrm{T}$ cell receptor zeta-chain and induce a regulatory phenotype in naive T cells. Journal of Immunology. 2006; 176:6752-6761.

88. Matteoli G, Mazzini E, Iliev ID, et al. Gut CD103+ dendritic cells express indoleamine 2,3dioxygenase which influences $\mathrm{T}$ regulatory/T effector cell balance and oral tolerance induction. Gut. 2010; 59:595-604. [PubMed: 20427394]

89. Hadis U, Wahl B, Schulz O, et al. Intestinal tolerance requires gut homing and expansion of FoxP3+ regulatory T cells in the lamina propria. Immunity. 2011; 34:237-246. [PubMed: 
21333554] This study shows that the induction of oral tolerance is a stepwise process highlighting the critical role of FoxP $3+\mathrm{T}$ regulatory cells that are induced by CD103+ dendritic cells.

90. Cassani B, Villablanca EJ, Quintana FJ, et al. Gut-tropic T cells that express integrin alpha4beta7 and CCR9 are required for induction of oral immune tolerance in mice. Gastroenterology. 2011; 141:2109-2118. [PubMed: 21925467]

91. Anjuere F, Luci C, Lebens M, et al. In vivo adjuvant-induced mobilization and maturation of gut dendritic cells after oral administration of cholera toxin. Journal of Immunology. 2004; 173:51035111.

92. Blazquez AB, Berin MC. Gastrointestinal dendritic cells promote Th2 skewing via OX40L. Journal of Immunology. 2008; 180:4441-4450.

93. Smit JJ, Bol-Schoenmakers M, Hassing I, et al. The role of intestinal dendritic cells subsets in the establishment of food allergy. Clin Exp Allergy. 2011; 41:890-898. [PubMed: 21477183]

94. Cardona ID, Cho SH, Leung DY. Role of bacterial superantigens in atopic dermatitis : implications for future therapeutic strategies. Am J Clin Dermatol. 2006; 7:273-279. [PubMed: 17007538]

95. Ganeshan K, Neilsen CV, Hadsaitong A, et al. Impairing oral tolerance promotes allergy and anaphylaxis: a new murine food allergy model. J Allergy Clin Immunol. 2009; 123:231-238. e234. [PubMed: 19022495]

96. Yang PC, Xing Z, Berin CM, et al. TIM-4 expressed by mucosal dendritic cells plays a critical role in food antigen-specific Th2 differentiation and intestinal allergy. Gastroenterology. 2007; 133:1522-1533. [PubMed: 17915221]

97. Zhao CQ, Li TL, He SH, et al. Specific immunotherapy suppresses Th2 responses via modulating TIM1/TIM4 interaction on dendritic cells. Allergy. 2010; 65:986-995. [PubMed: 20028372] 


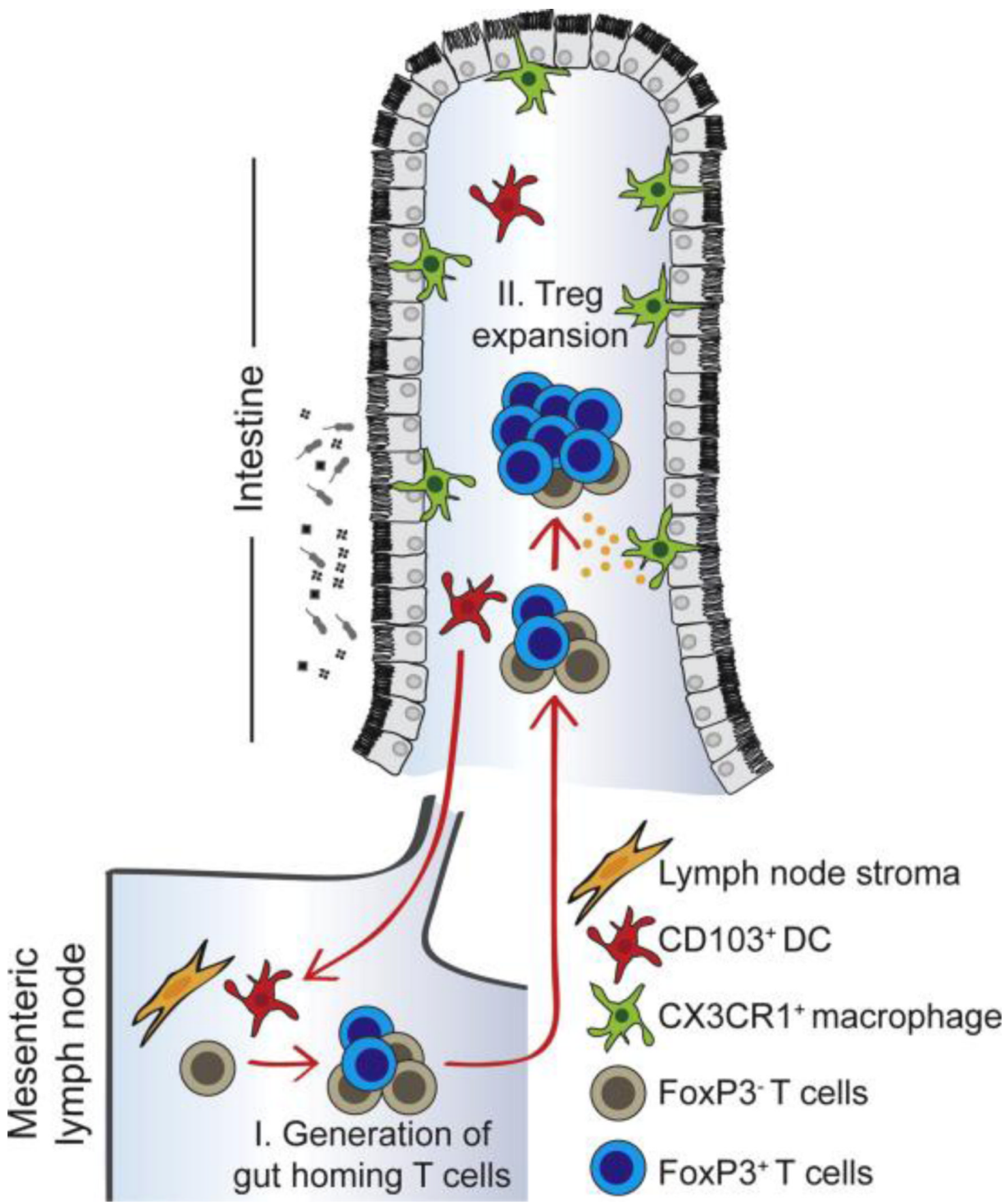

Figure 1.

After taking up antigen in the lamina propria, $\mathrm{CD}_{103^{+}}$dendritic cells (DCs) migrate to the mesenteric lymph node. $\mathrm{CD} 103^{+} \mathrm{DCs}$ present antigen to naïve $\mathrm{T}$ cells that are induced to differentiate into FoxP3-expressing T-regulatory cells (Tregs) and imprinted with a $4 \beta 7$ and CCR9. After homing back to the gut, $\mathrm{CX} 3 \mathrm{CR} 1^{+}\left(\mathrm{CD} 103^{-}\right)$cells secrete IL-10 to allow for local expansion of Tregs and induction of oral tolerance. (Adapted from Hadis et al. [89•]; copyright 2011, Elsevier; with permission.) 